\title{
Second-generation antipsychotics clinical pharmacy plan developed from hospital pharmacy to primary health care
}

\begin{abstract}
The growing role of hospital pharmacists in the ambulatory care setting challenges new changes. Drug distribution to Primary/Ambulatory Healthcare needs to reformulate a clinical pharmacy practice plan when presented with a patient having schizophrenia, according to criteria of rational drug use, equity and accessibility of the patient for sustained concentrations for several weeks indicated only for chronic therapy in patients who have trouble adhering to oral therapy that might achieve a markedly decline of positive, negative and cognitive symptoms. Therefore, these important features of long-acting injectable antipsychotics (LAIs, previously known as depot antipsychotics) need to be addressed on real-world practice. The purpose of the study is to develop drug distribution logistics for second-generation antipsychotics from Spanish Hospital Pharmacy to all Primary Health Care Sector (target population: Urban, Rural, and Homecare Support) from 2015 to 2016.
\end{abstract}

Keywords: drug distribution, antipsychotic agents, hospital pharmacy, primary health care, clinical pharmacy practice, deterioration, schizophrenia, injectable risperidone, paliperidone palmitate, aripiprazole
Volume 5 Issue 4 - 2017

\author{
Alberto Frutos Pérez-Surio, ${ }^{1,2}$ Roberto \\ Lozano Ortiz, ${ }^{3}$ Alejandro Martínez Crespo, ${ }^{4}$ \\ Alberto Apesteguía El Busto ${ }^{2}$ \\ 'Department of Microbiology, Preventive Medicine and Public \\ Health, Universidad de Zaragoza, Spain \\ 2Department of Pharmacy, Hospital Clínico Universitario \\ Lozano Blesa, Spain \\ ${ }^{3}$ Department of Pharmacy, Hospital Real de Nuestra Señora de \\ Gracia, Spain \\ ${ }^{4}$ Department of Pharmacy, Centro de Rehabilitación Psicosocial \\ Nuestra Señora Del Pilar, Spain
}

\begin{abstract}
Correspondence: Alberto Frutos Pérez-Surio, Department of Pharmacy, Hospital Clínico Universitario Lozano Blesa (Zaragoza), Avenida San Juan Bosco, Spain, Tel +34 9767657 00, Fax +34976 5659 95, Email ajfrutos@salud.aragon.es
\end{abstract}

Received: May 15, 2017 | Published: June 09, 2017

Abbreviations: ARI, aripiprazole; LAIs, long-acting injectable antipsychotics; PP, paliperidone palmitate; SGA, second-generation antipsychotics

\section{Introduction}

\section{Background}

The growing role of hospital pharmacists in the ambulatory care setting challenges new changes. Drug distribution to Primary/ Ambulatory Healthcare needs to re-formulate a clinical pharmacy practice plan when presented with a patient having schizophrenia, according to criteria of rational drug use, equity and accessibility of the patient for sustained drug concentrations for several weeks indicated only for chronic therapy in patients who have trouble adhering to oral therapy that might achieve a markedly decline of positive, negative and cognitive symptoms. ${ }^{1-4}$ Therefore, these important features of long-acting injectable antipsychotics (LAIs, previously known as depot antipsychotics) need to be addressed on real-world practice. ${ }^{5}$

Schizophrenia is a chronic disease, from the sphere of mental health, which is expressed as altered mental functions as well as disruptive behaviour. According to the criteria of the latest edition of Diagnostic and Statistical Manual of Mental Disorder (DSM-5) the most characteristic symptoms are delusional ideas, hallucinations, language disorganization, catatonic or severely disorganized behaviour, and the presence of negative symptoms. Its diagnosis requires that some of these symptoms be persistent (minimum duration greater than 1month), with signs of disturbance (either actively, residual or prodromic, for at least 6 months) and that there is social or occupational dysfunction during a part Significant time since the onset of the disturbance. Other clinical symptoms that may also be present are, among others, cognitive functioning deficits and mood disorders. Its prevalence is of the order of $0.45 \%$, with little variation between countries. The annual incidence of schizophrenia is about 15 per 100,000 people, and the risk of developing the disease during life is $0.7 \%{ }^{2}$ In studies conducted in Spain, a prevalence of 3.0 per 1,000 inhabitants per year in men is estimated, and 2.86 in women. ${ }^{6}$ The symptoms of this alteration usually begin between the 18 and 25years in the men, and between the 25 and 35years in the women. The forms of late onset, above 40years, are very rare. According to the World Health Organization (WHO), schizophrenia affects more than 21 million people worldwide and it is important to have a well-qualified procurement and supply management team. ${ }^{7}$ Patients diagnosed with schizophrenia die 12-15years earlier than the population mean, a difference that has increased in recent decades. ${ }^{8}$ Although some deaths are due to suicide, the main reason for this increase in mortality has been attributed to lifestyle, the premature development of cardiovascular diseases and the increased incidence of metabolic disorders.

Schizophrenia is a complex disorder of variable course in which complete remission is very difficult. There are recurrent forms, characterized by multiple psychotic episodes with periods of relative stability during which different levels of deterioration (negative symptoms, cognitive deterioration, and functional deterioration) are usually evident; In some cases, clinical remission between episodes can be achieved. At other times, the course is continuous so that there are always symptoms with a clinically relevant intensity (DSM-5). The annual relapse rate (defined as the worsening of symptoms or rehospitalisation) can reach $40-50 \%$; its prevention represents one of the main therapeutic objectives.

Antipsychotic drugs are at the heart of the treatment of 
schizophrenia. They have demonstrated their efficacy on psychotic symptoms (delusions, hallucinations, formal disorders of thought) and reduction of relapse rate. However, they lack demonstrated efficacy over other symptoms, such as primary negative symptoms and cognitive symptoms. ${ }^{9}$

\section{Purpose}

The aim of the study is to develop drug distribution logistics for second-generation antipsychotics from Spanish Hospital Pharmacy to all Primary Health Care Sector (target population: Urban, Rural, and Homecare Support) from 2015 to 2016.

\section{Adaptability}

It is necessary to implement storing conditions and drug distribution technology for atypical or second-generation of antipsychotics (SGA) for schizophrenia. The supply chain management will be agreed in each case between the Hospital Pharmacy Department and the corresponding Primary Healthcare, taking into account the population served. ${ }^{10-12}$ The qualitative content collected for each SGA. The quantitative content detailed in a list order.

The request to Pharmacy Department is performed by online database program, with data from: long-acting intramuscular formulation of risperidone; paliperidone palmitate; and prolongedrelease suspension for injection of aripiprazole. Following the Instruction of November $30^{\text {th }}$ of 2015 the Aragon Health Service,
Hospital Pharmacy Department manages the documentation of patients who require treatment with injectable aripiprazole, as well as risperidone and paliperidone palmitate depot injection, and shall request both at the beginning, change or renewal of treatment with the appropriate form of treatment parenteral long-acting antipsychotics.

\section{Significance}

This delivery of this paper might have important impact on international pharmacy and pharmacology advancement, with decreased consumption of injectable Risperidone, Paliperidone palmitate (PP), and Aripiprazole (ARI), and better management and control, mainly in outpatient specialty care.

\section{Results}

1480 antipsychotics were send to 23 healthcare centres and 3 specialist mental-health clinic $(252,297 €)$. Use of Risperidone decreased along study period, and PP appears to increase, mainly used with high-doses. ARI trends remain stable. In example, the use of ARI (only in 2016) was (Table $1 \&$ Table 2):

Additionally, in the framework of the challenge of rapid change in healthcare, the Spanish Agency of Medicines and Medical Devices reports shortages of fluphenazine decanoate $25 \mathrm{mg} / \mathrm{mL}$ solution for injection; so we implemented access to medicinal products in special situations prior authorization under Royal Decree 1015/2009.

Table I Use of Risperidone decreased along study period

\begin{tabular}{llllll}
\hline \multirow{2}{*}{ Drug } & Doses & \multicolumn{3}{l}{ Number of treatments } & \multicolumn{2}{l}{ Cost $(€)$} & \\
\cline { 3 - 6 } & & 2015 & 2016 & 2015 & 2016 \\
\hline Risperidone & $25 \mathrm{mg}, 37.5 \mathrm{mg}$, and 50mg & 2128 & 1916 & $241,434.41$ & $216,873,11$ \\
Paliperidone & $50 \mathrm{mg}, 75 \mathrm{mg}, 100 \mathrm{mg}$, and 150mg & 2031 & 2532 & $626,925.90$ & $765,765.78$ \\
Aripiprazole & $300 \mathrm{mg}$ and 400mg & 13 & 283 & 2858,16 & $68,701.59$ \\
\hline
\end{tabular}

Table 2 ARI trends remain stable

\begin{tabular}{lllll}
\hline ARI & $\begin{array}{l}\text { Psychiatric service at } \\
\text { day hospital }\end{array}$ & $\begin{array}{l}\mathbf{2 3} \text { primary } \\
\text { healthcare centres }\end{array}$ & $\begin{array}{l}\text { Psychosocial } \\
\text { rehabilitation center }\end{array}$ & $\begin{array}{l}\mathbf{3} \text { Mental } \\
\text { health units }\end{array}$ \\
\hline $\begin{array}{l}\text { Total of } \\
\text { patients }\end{array}$ & 22 & 16 & 1 & $\begin{array}{l}\text { Socio-sanitary } \\
\text { center }\end{array}$ \\
\hline
\end{tabular}

\section{Conclusion}

The results presented suggest a decreased consumption of injectable risperidone, on the contrary of PP increased dose, ${ }^{13}$ mainly in outpatient specialty care. The low impact of ARI use might not be explained on the basis of the study, and future prospective and multidisciplinary works should be done.

\section{Acknowledgements}

None.

\section{Conflict of interest}

Author declares that there is no conflict of interest.

\section{References}

1. Tandon R, Gaebel W, Barch DM, et al. Definition and description of schizophrenia in the DSM-5. Schizophr Res. 2013;150(1):3-10.

2. Tandon R, Keshavan MS, Nasrallah HA. Schizophrenia, "just the facts" what we know in 2008. Part 2. Epidemiology and etiology." Schizophr Res. 2008;102(1-3):1-18.

3. Leucht S, Cipriani A, Spineli L, et al. Comparative efficacy and tolerability of 15 antipsychotic drugs in schizophrenia: a multiple-treatments meta-analysis. Lancet. 2013;382(9896):951-962.

4. Kishimoto T, Robenzadeh A, Leucht C, et al. Long-acting injectable vs oral antipsychotics for relapse prevention in schizophrenia: a meta-analysis of randomized trials. Schizophr Bull. 2014;40(1):192-213. 
5. Miroshnichenko II, Baymeeva NV, Ivanova SA, et al. A Case of a Schizophrenic Patient with Unusual Pharmacogenetics Profile. Pharm \& Pharmacol Int J. 2017;5(3):00121.

6. Ayuso-Mateos JL, Gutierrez-Recacha P, Haro JM, et al. Estimating the prevalence of schizophrenia in Spain using a disease model. Schizophr Res. 2006;86(1-3):194-201.

7. Improving access to and appropriate use of medicines for mental disorders. Geneva: World Health Organization, Calouste Gulbenkian Foundation; 2017.

8. Saha S, Chant D, McGrath J. A systematic review of mortality in schizophrenia: is the differential mortality gap worsening over time? Arch Gen Psychiatry. 2007;64(10):1123-1131.

9. Davis JM, Chen N, Glick ID. A meta-analysis of the efficacy of second-generation antipsychotics. Arch Gen Psychiatry. 2003;60(6):553-564.
10. Management of schizophrenia. Scottish Intercollegiate Guidelines Network. Edinburgh; 2013.

11. Schizophrenia: Core interventions in the treatment and management of schizophrenia in primary and secondary care (update). National Collaborating Centre for Mental Health Commissioned by the National Institute for Health and Clinical Excellence. UK; 2009.

12. Khanna P, Suo T, Komossa K, et al. Aripiprazole versus other atypical antipsychotics for schizophrenia. Cochrane Database Syst Rev. 2013;(2):CD006569.

13. Combination and High-Dose Atypical Antipsychotic. Therapy in Patients with Schizophrenia: Systematic Review. CADTH Technol Overv. 2012;2(3):e2301. 